\title{
Cultural Influence on Pupils' Understanding of Conception, Birth of Twins and Sex Determination in Kenya
}

\author{
Fred N. Keraro ${ }^{1}$, Mark I. O. Okere ${ }^{1} \&$ Zephania O. Anditi ${ }^{1}$ \\ ${ }^{1}$ Department of Curriculum, Instruction \& Educational Management, Egerton University, Kenya \\ Correspondence: Fred N. Keraro, Department of Curriculum, Instruction \& Educational Management, Egerton \\ University, P. O. Box 536-20115, Egerton, Kenya. E-mail: fred.keraro@yahoo.com
}

\author{
Received: February 13, 2013 Accepted: February 28, 2013 Online Published: April 26, 2013 \\ doi:10.5539/ies.v6n5p11 \\ URL: http://dx.doi.org/10.5539/ies.v6n5p11
}

The study was financed by Kenya's National Council for Science \& Technology (NCST)

\begin{abstract}
This study investigated the extent to which primary and secondary school pupils believe in cultural interpretations of the biological concepts of conception, birth of twins and sex determination and the influence of education level and gender. Cross-sectional survey research design was used. The target population was Standard Seven (7th grade in the primary school cycle), Form one and Form Three (1st and 3rd grades in the secondary school cycle) pupils in 10 districts in Kenya. A total of 3452 pupils (1875 girls and 1577 boys) participated. The pupils were drawn from 15 primary and 31 secondary schools. A questionnaire was used to gather information from the pupils. The findings indicate that pupils believe in the cultural interpretations of biological phenomena investigated. The findings further indicate that there is a relationship between the pupils' believe in cultural interpretations and the academic grade level and gender. The findings from this study, therefore, inform curriculum developers that cultural believes are likely to militate against the pupils' learning of science. It is recommended that teachers discuss cultural interpretations of scientific concepts before introducing them in their lessons.
\end{abstract}

Keywords: science, culture, beliefs, conception, twins, sex determination

\section{Introduction}

The world over, the premium placed on science education is high. It is seen as an important instrument that should facilitate sustainable development, poverty reduction and improve the quality of life as a whole. High-quality science education is required not only for sustaining a lively scientific community that is able to address global problems like global warming and pandemics, but also to bring about and maintain a high level of scientific literacy in the general population (van Eijck \& Roth, 2007). UNESCO world conference on science in Budapest, Hungary declared that science should be at the service of humanity as a whole and contribute to providing everyone with a deeper understanding of nature and society, a better quality of life and a sustainable and healthy environment for present and future generations (UNESCO, 1999). To achieve this, there needs to be effective teaching and learning of science at all levels, more importantly at the primary and secondary school levels.

There are a number of factors that militate against effective teaching and learning of science. For a long time poor performance or under achievement in science education in Africa has been attributed to inappropriate teaching strategies, unqualified science teachers, lack of appropriate teaching - learning resources and the abstractness of science. Growing evidence from empirical studies now strongly suggests that culture is, indeed, one of these factors ( Shumba, 1995; Anmuah-Mensah, 1998, Okere \& Keraro, 2002). Cobern and Aikenhead (1998) have argued that learning is about making meaning within a cultural milieu. This perspective has received minimal attention in the context of teaching and learning of science in Africa.

Culture is the label anthropologists give to the structured customs and underlying worldview assumptions that govern people's lives (Kraft, 1998). Culture can also be interpreted as a people's way of life, their design for living, their way of coping with their biological, physical and social environment. The attributes that define culture include language, social structures, skills, customs, norms, attitudes, values, beliefs, expectations, 
cognition, conventional artifacts, technological know-how and worldview (Cobern \& Aikenhead, 1998). A worldview shapes how people perceive, understand and interpret natural phenomena and all other events in their environment. According to Ogunniyi (1989) traditional African culture relates to the organized body of knowledge, beliefs, values, customs, conventions, routines, and a way of life essentially African in origin, development and orientation, and which are usually passed by word of mouth or example from one generation to another. Cobern (1993) includes gender as an important cultural element that influences the learning of science. Indeed, in many African traditional communities, boys and girls are from time to time separately taught about their respective gender roles. The emphasis in each case is on what directly concerns them in their future lifes as men and women, husbands and wives, fathers and mothers and what society expects from them. Girls in such cases may receive lessons on motherhood, conception, child bearing and child care, and nutrition. Boys on the other hand receive instruction on their role as leaders in families, technologists, and problem solvers in society and any other roles that are perceived to be exclusively within the male domain. This certainly is an enhancement of gender stereotyping which would influence the learning of formal science. This would, therefore, suggest that there are likely to be gender variations in the learners' prior conceptions of some of the natural/scientific phenomena and thus the learning of formal science in school. In the context of this paper, culture refers to the established way of life or socially transmitted results of human experience through which a group of people carry their way of life. It includes language, customs, morals, tools, beliefs and belief systems, institutions, knowledge and worldview.

\section{Culture, Worldview and Constructivist Learning}

Constructivism as a learning theory has its foundations in Jean Piagets's theory of 'genetic epistemology'. It is based on observation and a scientific study about how people learn. Within the constructivist learning model, learning is an active process in which learners have to actively construct meanings from their own experiences to build unique representations of content or change their prior conceptions (Good \& Brophy, 1995; Atwater, 1994; Driver, 1989; Driver \& Bell, 1986; Piaget, 1964). Lewis and Linn (2003) pointed out that students' rely on intuitive conceptions to explain events not specifically studied in class. Intuitive conceptions refer to ideas developed as a result of interacting with the natural world. Constructivism views learners as cognitively active participants in the process of constructing meanings from their experiences. Meaningful learning occurs by interpreting a message and not by receiving a transmission. Critical, therefore, in the learning of science within the constructivist learning model is a learner's prior conceptions. Construction thus would involve interpretations influenced by prior knowledge, and this suggests a conceptualization of scientific knowledge in which it is reasonable to expect culture specific understanding of science concepts (Cobern, 1996). Driver's (1989) observation that cognitive ethnographies undertaken in classroom settings indicate that learners' prior ideas are an important factor in their understanding of formal science further reinforces this argument.

Atwater (1994) points out that culture is an important aspect of a child's development. It is a strong designer of human nature, experiences and their interpretations. It is also acknowledged that a child's conceptual development is a function of several factors including the social-cultural background, mental maturity and environment (Ogunniyi, 1985). By the time African children are being introduced to formal science in school, they have already been exposed to their cultural worldview and have a repertoire of cultural beliefs, myths and explanations for physical and biological phenomena. They would also have participated in a wide range of cultural practices and consequently developed conceptual schemes that come to bear on the learning of science. Their worldview, therefore, shapes how they perceive, understand and interpret phenomena because their culture of origin conceptions come into play.

Formal science has been presented in the literature as originating from the West hence reflects the Western worldview and mode of thinking (Pauka, Treagust \& Waldrip, 2005; Aikenhead \& Jegede, 1999; Cobern \& Aikenhead, 1998; Cobern,1996; Ogunniyi, 1988; Odhiambo, 1972). This thus makes school science alien to students from African and other non-Western cultures. In Moddock's (1981) words, school science is like a foreign culture to them. Morris (1983) and Cobern (1993) argue that learning does not take place in a vacuum, it occurs against the background of a view of the world and society. Students, therefore, come into a classroom with their own knowledge base on science concepts based on their socio-cultural interactions and experiences. It has been pointed out that African communities, and more particularly those in rural areas often hold deep rooted traditional beliefs about certain things which in some cases do not conform to conventional scientific explanations (Gray, 1998). Therefore, for African children to learn formal science is to acquire a new culture, a new worldview. Aikenhead and Jegede (1999) refer to this as border crossing, crossing the border from African culture to the culture of science. 
The study reported in this paper investigated the extent to which students believe in cultural interpretations of the biological concepts of conception, the birth of twins, and sex determination and evaluated the influence of these interpretations on the learning of science in schools.

\section{Purpose and Objectives of the Study}

The study was designed to investigate the extent to which primary and secondary school students believe in cultural interpretations of selected biological concepts and how such interpretations influence their conceptualization of these concepts. Its specific objectives were:

- To find out if primary and secondary school pupils believe in cultural interpretations of selected biological phenomena and how such interpretations influence conceptualization of the phenomena.

- To investigate the relationship between pupils' believe in cultural interpretations of selected biological phenomena and level of education.

- To investigate the relationship between pupils believe in cultural interpretations of phenomena and gender.

\section{Research Questions}

The following research questions were used to guide the study.

- Do primary and secondary school pupils believe in the cultural interpretations of selected biological phenomena?

- Is there a relationship between pupils' beliefs in cultural interpretations of selected biological phenomena and academic level of education?

- Is there a relationship between pupils' beliefs in cultural interpretations of selected biological phenomena and gender?

\section{Methodology}

The simultaneous cross-sectional survey research design was used in this study. The design was found to be suitable for obtaining pupils' cultural interpretations of the selected biological phenomena at one point in time. Schools were used as sampling units and a total of 3452 pupils (1875 girls and 1577 boys) were sampled. This comprised 625 and 2827 pupils from primary and secondary schools respectively. The National Council for Science and Technology (NCST) in the Ministry of Higher Education that is mandated to authorize academic research in Kenya authorized and financed the researchers to conduct this study in public schools.

The primary school cycle in Kenya takes 8 years. It starts from standard 1 (grade 1) to standard 8 (grade 8 ) and thus takes pupils 8 years to graduate and join the secondary school cycle. The secondary school cycle takes 4 years with form 1 being the first grade and form 4 the final grade. The study sample was selected from standard seven pupils (seventh grade in the primary school cycle) and forms one and three pupils (first and third grade in the secondary school cycle). The age of pupils joining primary 1 is 6 years. Therefore, the average ages of pupils included in the study sample are 12, 14, and 16 for standard 7, form 1, and form 3 respectively. The sample was purposively drawn from 15 rural primary and 31 rural secondary schools from ten districts in five regions (formerly provinces) in Kenya. The districts were purposively selected to ensure that the pupils from each district represented one cultural/ethnic community. Table 1 shows the distribution of the study sample.

Table 1. Distribution of number of schools and pupils per region and district

\begin{tabular}{llllllll}
\hline Region & District & \multicolumn{2}{l}{ No and school type } & No and gender of pupils & & Total \\
\hline & Boys & Girls & Primary & Primary & Form 1 & Form 3 & \\
& Sec & Sec & & & & &
\end{tabular}

Boys Girls Boys Girls Boys Girls

$\begin{array}{llllllllllll}\text { Nyanza } & \text { Rachuonyo } & 2 & 2 & 2\} & & & & & & & \\ & \text { Kisii } & 2 & 2 & 2\} & 88 & 84 & 199 & 280 & 188 & 268 & 1107 \\ & \text { Kuria } & - & 1 & -\} & & & & & & & \\ \end{array}$




\begin{tabular}{llllllllllll}
\hline Eastern & $\begin{array}{l}\text { Meru } \\
\text { South }\end{array}$ & 2 & 2 & $2\}$ & & & & & & & \\
& & & & & 46 & 113 & 203 & 166 & 182 & 171 & 881 \\
& Embu East & 2 & 2 & $2\}$ & & & & & & & \\
Coast & Kilifi & 1 & 1 & $1\}$ & & & & & & & \\
& Kwale & 1 & 1 & $1\}$ & 27 & 75 & 72 & 87 & 58 & 81 & 400 \\
Central & Nyeri & 1 & 1 & 1 & - & 16 & 43 & 40 & 46 & 38 & 183 \\
Rift & Nandi & 2 & 2 & $2\}$ & & & & & & & \\
Valley & Bomet & 2 & 2 & $2\}$ & 80 & 96 & 168 & 180 & 177 & 180 & 881 \\
& TOTAL & & & & & & & & & & 3452 \\
\hline
\end{tabular}

\section{Instrumentation}

A questionnaire having three items was administered by the researchers with assistance from primary science and biology teachers in the respective schools. The items gave suggestions concerning cultural interpretations of selected biology concepts (conception, birth of twins\& sex determination) drawn from the topic reproduction. The concepts selected are covered in both primary science and secondary school biology albeit to varying depths with the exception of sex determination which is introduced in form 3 in secondary school biology. However, these concepts attract a lot of attention in traditional cultural communities and thus have a number of cultural interpretations. The following are the survey items used in this study:

\section{Prenancy}

1. Two form three girls were having a discussion on the most likely period of conception (becoming pregnant). One girl suggested that it is:

(i) If they have sexual intercourse when they are having periods.

The other girl stated that it is:

(ii) Any time they have sexual intercourse.

Do you agree with any of the explanations?

YES [ ] NO []

Explain your answer

\section{Birth of Twins}

2. Janet gave birth to twins. The elders in her village explained that this happened because of one of the following reasons:

i. Janet must have eaten 'twin' bananas (double) or eggs with twin (double) yolk when she was pregnant.

ii. It was a curse.

Do you agree with any of these explanations?

YES [ ] NO [ ]

Explain your answer.

\section{Birth of Daughters}

3. In our communities, it is common to find parents who have got daughters ONLY. The explanation given is that the mother is not capable of giving birth to a son.

Do you agree with this explanation?

YES [ ] NO []

Explain your answer. 


\subsection{Data Analysis}

Content analysis was applied on the qualitative data generated. The data was analyzed to establish the extent to which the pupils believed in the cultural interpretations. The analysis also evaluated whether the believes vary with grade/academic level and gender.

\subsection{Results}

\subsubsection{Pupils' Cultural Explanations of the Period of Conception}

The item pregnancy was used to investigate the pupils' believe in cultural interpretations of the most likely period of conception and their understanding of the menstrual cycle. A total of 2,777 pupils responded to this item and 1,592 of them (57.33\%) agreed with one of the cultural explanations given or suggested a more 'plausible' one. The remaining 1,185 (46.67\%) pupils disagreed and some of them gave either a scientifically acceptable explanation or none at all in some cases. The pupils' responses were categorized as either being cultural or scientific explanations. The following are sample responses.

\section{Scientific explanations}

(i) Pregnancy takes place during ovulation.

(ii) When experiencing periods the ova will have died hence there will be no fertilization.

\section{Cultural explanations}

(i) Having sex during periods.

(ii) Having sex any time.

(iii) When you have sex with an adult.

(iv) It is during periods the egg is released.

(v) During periods the ovum is ready for fertilization.

The pupils' responses were further analysed on the basis of level of education and gender. The results are presented in tables 2 and 3.

Table 2. Numbers and percentages of pupils agreeing or disagreeing with suggested cultural interpretations of the likely period of conception

\begin{tabular}{llllll}
\hline $\begin{array}{l}\text { Education } \\
\text { Level }\end{array}$ & $\begin{array}{l}\text { Total no. } \\
\text { respondents }\end{array}$ & of & Total agreed & Total disagreed & \\
\hline Standard 7 & 415 & No & $\%$ & No & $\%$ \\
Form 1 & 1160 & 295 & 71.08 & 120 & 28.92 \\
Form 3 & 1202 & 698 & 60.17 & 462 & 39.83 \\
Overall & 2777 & 599 & 49.83 & 603 & 50.17 \\
\hline
\end{tabular}

The result in table 2 indicates that $71.08 \%$ of the pupils in standard 7 believed in the cultural interpretations of the likely period of conception followed by those in form $1(60.17 \%)$ and form three $(49.83 \%)$. The trend that emerges shows a clear relationship between the pupils' level of education and their conceptualization of the period of conception. A majority of the pupils in standard 7 believe in cultural interpretations and this progressively decrease as they move through to the upper grades in the school system but are never eliminated. This would suggest that the learning experiences provided in school science enable learners to progressively erode the cultural interpretations though they are never completely eliminated. 
Table 3. Numbers and percentages of pupils agreeing or disagreeing with suggested cultural explanations of the likely period of conception by education level and gender

\begin{tabular}{llllll}
\hline Education Level & No & \multicolumn{2}{l}{ Agreed } & \multicolumn{2}{l}{ Disagreed } \\
\hline Boys & & No & $\mathbf{\%}$ & No & $\mathbf{\%}$ \\
Standard 7 & 199 & 142 & 71.36 & 57 & 28.64 \\
Form 1 & 583 & 392 & 67.24 & 191 & 32.76 \\
Form 3 & 584 & 401 & 68.66 & 183 & 31.34 \\
Sub total & $\mathbf{1 3 6 6}$ & $\mathbf{9 3 5}$ & $\mathbf{6 8 . 4 5}$ & $\mathbf{4 3 1}$ & $\mathbf{3 1 . 5 5}$ \\
Girls & & & & & \\
Standard 7 & 216 & 153 & 70.83 & 63 & 29.17 \\
Form 1 & 577 & 306 & 53.04 & 271 & 46.97 \\
Form 3 & 618 & 198 & 32.04 & 420 & 67.96 \\
Sub total & $\mathbf{1 4 1 1}$ & $\mathbf{6 5 7}$ & $\mathbf{4 6 . 5 6}$ & $\mathbf{7 5 4}$ & $\mathbf{5 3 . 4 4}$ \\
Overall & $\mathbf{2 7 7 7}$ & $\mathbf{1 5 9 2}$ & $\mathbf{5 7 . 3 3}$ & $\mathbf{1 1 8 5}$ & $\mathbf{4 2 . 6 7}$ \\
\hline
\end{tabular}

Table 3 shows that the boys and girls in standard 7 equally believed in cultural explanations of the likely period of conception ( $71.36 \%$ and $70.83 \%$ respectively). This pattern changes in forms 1 and 3 where the percentage of girls holding cultural explanations drops drastically compared to that of boys. The percentage of the girls who agreed with the cultural explanations is $53.04 \%$ and $32.04 \%$ for those in forms 1 and 3 respectively. As the girls mature, they progressively discard the cultural explanations, something that is not noticeable among boys. It would appear that a majority of the older girls who have reached the stage of puberty have sought explanations for the physiological process they are going through from those who have had the experience and, therefore, have a better understanding of the menstrual cycle. The percentage of boys in form 1 and 3 holding cultural explanations is at par (67.24\% and $68.66 \%$ respectively).

\subsubsection{Pupils' Cultural Interpretations of the Birth of Twins}

The item birth of twins was used to investigate pupils' believe in cultural interpretations of the birth of twins. A total of 3252 pupils gave responses to this item and 422 of them (12.98\%) agreed with one of the suggested cultural explanations or gave a more "plausible, one. The remaining 2830 pupils $(87.02 \%)$ disagreed. Some of those who disagreed gave scientifically acceptable explanations while the rest did not give any alternative interpretations. The following are sample responses.

\section{Scientific explanations}

(i) Birth of twins is caused when two ova are fertilized at same time.

(ii) When fertilized ovum splits into two.

\section{Cultural explanations}

(i) When sperm moves at high speed and hit the egg and break it into two.

(ii) Sex between male and female.

(iii) When two sperms fertilize together.

(iv) Twins are a blessing from God.

(v) When you eat double (twin) banana.

(vi) It is believed that a man is very strong.

(vii) It depends if any of your relatives or your mother gave birth to twins.

(viii)Caused by God.

The pupils' responses were further analyzed on the basis of level of education and gender. The results are presented in tables 4 and 5 . 
Table 4. Numbers and percentages of pupils agreeing or disagreeing with suggested cultural explanations of the birth of twins by education level

\begin{tabular}{cccccc}
\hline $\begin{array}{c}\text { Education } \\
\text { Level }\end{array}$ & $\begin{array}{c}\text { Total no. of } \\
\text { respondents }\end{array}$ & \multicolumn{2}{c}{ Total agreed } & \multicolumn{2}{c}{ Total disagreed } \\
\hline Standard 7 & 588 & 177 & 30.10 & 411 & $\mathbf{\%}$ \\
Form 1 & 1238 & 137 & 11.07 & 1101 & 88.90 \\
Form 3 & 1426 & 108 & 7.57 & 1318 & 92.43 \\
Overall & $\mathbf{3 2 5 2}$ & $\mathbf{4 2 2}$ & $\mathbf{1 2 . 9 8}$ & $\mathbf{2 8 3 0}$ & $\mathbf{8 7 . 0 2}$ \\
\hline
\end{tabular}

The result shows that on a whole fewer pupils believed in cultural explanations of birth of twins at all the three grade levels. Among the standard 7 pupils $30.10 \%$ believed in the cultural explanations compared to $11.07 \%$ and $7.57 \%$ of those in forms 1 and 3 three respectively. The result also shows a progressive decrease of these cultural explanations from standard 7 to form 3 . This is an indication that exposure to formal science in school facilitates learners' 'border crossing from traditional culture to the culture of science'.

Table 5. Numbers and percentages of pupils agreeing or disagreeing with suggested cultural explanations of the birth of twins by education level and gender

\begin{tabular}{llllll}
\hline Education Level & $\begin{array}{l}\text { No of } \\
\text { respondents }\end{array}$ & Agreed & \multicolumn{3}{l}{ Disagreed } \\
\hline Boys & & No & $\mathbf{\%}$ & No & $\mathbf{\%}$ \\
& 248 & 65 & 26.21 & 183 & 73.79 \\
Standard 7 & 707 & 68 & 9.62 & 639 & 90.38 \\
Form 1 & 725 & 44 & 6.07 & 681 & 93.93 \\
Form 3 & $\mathbf{1 6 8 0}$ & $\mathbf{1 7 7}$ & $\mathbf{1 0 . 5 4}$ & $\mathbf{1 5 0 3}$ & $\mathbf{8 9 . 4 6}$ \\
Sub total & & & & & \\
Girls & 271 & 47 & 17.34 & 224 & 82.66 \\
Standard 7 & 601 & 68 & 11.31 & 533 & 88.69 \\
Form 1 & 700 & 63 & 9.00 & 637 & 91.00 \\
Form 3 & $\mathbf{1 5 7 2}$ & $\mathbf{1 7 8}$ & $\mathbf{1 1 . 3 2}$ & $\mathbf{1 3 9 4}$ & $\mathbf{8 8 . 6 8}$ \\
Sub total & $\mathbf{3 2 5 2}$ & $\mathbf{3 5 4}$ & $\mathbf{1 0 . 8 9}$ & $\mathbf{2 8 9 8}$ & $\mathbf{8 9 . 1 1}$ \\
\hline Overall & & & & &
\end{tabular}

The result in table 5 shows that when the pupils' responses are analyzed by gender the trend given is similar to that of the grade levels where a majority of those holding cultural meanings are in the lower grade with a progressive decline to the higher grades. There also appears to be a gender difference within grade levels. The percentage of standard 7 boys accepting cultural interpretations $(26.21 \%)$ is much higher than that of girls (17.34\%). This trend however reverses in forms 1 and 3 where more girls accept cultural interpretations compared to boys.

\subsubsection{Pupils' Cultural Interpretations of Sex Determination}

The item birth of daughters was used to investigate pupils' believe in cultural interpretations of sex determination. A total of 2252 pupils gave responses to this item and 279 of them (12.39\%) agreed with one of the suggested cultural explanations or gave a more 'plausible' one. The remaining 1973 pupils (87.61\%) disagreed. Some of those who disagreed gave scientifically acceptable explanations while the rest did not give any alternative interpretations. The following are sample responses. 


\section{Scientific explanations}

(i) A mother always produces $\mathrm{X}$ chromosomes and father produces $\mathrm{X}$ and $\mathrm{Y}$ chromosomes. It is possible that the father is only producing $X$ chromosomes which make up a girl.

(ii) Baby boys are determined by the chromosome $\mathrm{Y}$ of the man.

\section{Cultural explanations}

(i) Mother can't give birth to a son.

(ii) Sperms of man are not strong.

(iii) It is due to inheritance.

(i) This is a result of father staying in kitchen most of the time when he was young.

(ii) This is because the mother had many daughter cells compared to the father.

Table 6. Numbers and percentages of pupils agreeing or disagreeing with suggested cultural interpretations of sex determination by grade level

\begin{tabular}{llllll}
\hline $\begin{array}{l}\text { Education } \\
\text { Level }\end{array}$ & $\begin{array}{l}\text { Total no. of } \\
\text { respondents }\end{array}$ & \multicolumn{2}{l}{ Total agreed } & Total disagreed \\
\hline Standard 7 & 348 & No & $\mathbf{\%}$ & No & $\%$ \\
Form 1 & 863 & 85 & 24.43 & 263 & 75.57 \\
& & 99 & 11.47 & 764 & 88.53 \\
Form 3 & 1041 & 95 & 9.13 & 946 & 90.87 \\
Overall & $\mathbf{2 2 5 2}$ & $\mathbf{2 7 9}$ & $\mathbf{1 2 . 3 9}$ & $\mathbf{1 9 7 3}$ & $\mathbf{8 7 . 6 1}$ \\
\hline
\end{tabular}

The result shows that only $12.39 \%$ of the study sample believed in cultural interpretations of sex determination. There is, however, variation between the grades/education level with the highest percentage being in standard 7 $(24.43 \%)$ and the lowest (9.13\%) in form 3. It is also important to note that though this concept is covered in the topic genetics in secondary school biology in form 3, pupils in standard 7 and form 1 have some' ideas' about it. These ideas must have been formed through their socio-cultural interactions.

Table 7. Numbers and percentages of pupils agreeing or disagreeing with suggested cultural interpretations of sex determination by grade level and gender

\begin{tabular}{llllll}
\hline Education Level & No & Agreed & \multicolumn{3}{l}{ Disagreed } \\
\hline Boys & & No & \% & No & $\%$ \\
Standard 7 & 154 & 47 & 30.52 & 107 & 69.48 \\
Form 1 & 450 & 53 & 11.78 & 397 & 88.22 \\
Form 3 & 434 & 52 & 11.98 & 382 & 88.02 \\
Sub Total & $\mathbf{1 0 3 8}$ & $\mathbf{1 5 2}$ & $\mathbf{1 4 . 6 4}$ & $\mathbf{8 8 6}$ & $\mathbf{8 5 . 3 6}$ \\
Girls & & & & & \\
Standard 7 & 194 & 38 & 19.59 & 156 & 80.41 \\
Form 1 & 413 & 46 & 11.14 & 367 & 88.86 \\
Form 3 & 607 & 43 & 7.08 & 564 & 92.92 \\
Sub Total & $\mathbf{1 2 1 4}$ & 127 & $\mathbf{1 0 . 4 6}$ & $\mathbf{1 0 8 7}$ & $\mathbf{8 9 . 5 4}$ \\
Overall & $\mathbf{2 2 5 2}$ & $\mathbf{2 7 9}$ & $\mathbf{1 2 . 3 9}$ & $\mathbf{1 9 7 3}$ & $\mathbf{8 7 . 6 1}$ \\
\hline
\end{tabular}


The result indicates that on a whole there is a gender variation in pupils' believe in cultural explanations of the determination of a child's sex. The percentage of boys accepting cultural explanations $(14.65 \%)$ is slightly higher than that of girls (12.39\%). This is more pronounced among the standard seven pupils where $30.52 \%$ of the boys accept cultural explanations compared to $19.59 \%$ of the girls. Though the gender variation among the form 1 and 3 pupils is not pronounced, it is important to note that the overall trend is maintained where more boys accept cultural interpretations at all levels.

\section{Discussion}

The results in this study have revealed that a good fraction of the pupils in both the primary and secondary schools in rural schools in Kenya hold cultural interpretations of the biology concepts that were investigated. They accept what Lewis and Linn (2003) refer to as intuitive conceptions to explain concepts they may have not encountered in formal science lessons. For instance the standard 7 and form 1 pupils had ideas on how the sex of a child is determined, a concept that they have not covered in primary science and form 1 biology lessons. There, indeed, was no major variation in the interpretations given by pupils from the different ethnic communities sampled in this study. There is also a strong indication that these explanations are coming from the pupils' socio-cultural environments. Among concepts investigated, conception attracted the highest percentage of pupils holding cultural interpretations and hence was the least understood by pupils at all levels.

In all cases, there was a progressive decline of the cultural interpretations from the lowest to the highest grade included in this study. Anamuah-Mensah (1998) explored the extent of native science beliefs held by students in secondary and tertiary institutions in Ghana. The study revealed that a substantial proportion firmly held native science beliefs. The study further revealed that formal education gradually eroded these beliefs but did not eliminate them. The results in our study support Anamuah-Mensah's findings. Ogunniyi (1984) conducted a study on the youth in Southern Nigeria to investigated the relative influence of supernatural forces among the Yuroba youth. One of the conclusions made from this study is that the scientific worldview may not be able to completely displace the people's traditional world outlook even after a thorough exposure to formal science. In some cases, pupils hold both cultural and scientific interpretations of a concept without any conflict but their responses depend on the context in which they find themselves.

The results from the current study further reveal that the extent to which cultural interpretations are held by pupils varies with gender. This contradicts one of the conclusions from Ogunniyi's (1984) study which indicates that the gender of the people does not have any significant influence on their traditional worldview. A proportionately higher number of boys held cultural interpretations of conception and sex determination compared to girls at all levels. This variation is more pronounced for the item pregnancy. This supports Cobern's (1993) argument that gender is a cultural variable that would influence pupils' learning of formal science. Indeed, from the researchers' cultural backgrounds, some concepts covered in biology are taboo and are never discussed openly and freely between adults and the youth, more especially between the opposite sexes (men and women or boys and girls) and may in such circumstances not be effectively covered even in science lessons. However, these concepts are openly discussed among peers or their seniors of the same sex. This would explain the gender variations observed in this study. All the concepts covered in this study fall in this category.

\section{Conclusions}

The findings from this study provide evidence that both the primary and secondary school pupils believed in cultural interpretations of biological concepts investigated and this militates against their understanding of these concepts . This would also apply to other biological and physical phenomena. The findings also indicate that there is a relationship between the pupils' believe in cultural interpretations and the level of education. Believe in cultural interpretations gradually declines with increasing exposure to formal science but is never eliminated. There is also a relationship between pupils' believe in cultural interpretations and gender. This is more pronounced at lower levels and also declines with more exposure to formal science.

For effective teaching and learning of science cultural interpretations of scientific or natural phenomena need to be brought to the fore. This would enable science teachers to provide learning experiences that can effectively challenge these interpretations and allow learners to change their prior conceptions. Science teacher education should emphasize the use interactive approaches that require active participation of learners in science lessons. This would enable them to actively construct knowledge for themselves and, therefore, engage in meaningful learning and thus enhance what Aikenhead and Jegede (1999) have referred to as border crossing. This would enhance a smooth border crossing from the African culture to the culture of science. Indeed, for effective teaching and learning of science, the starting point should be the learners' existing knowledge. 


\section{References}

Aikenhead G. S., \& Jegede O. J. (1999). Cross-Cultural Science Education: A cognitive Explanation of a Cultural Phenomenon. Journal of Research in Science Teaching, 36(3), 269-287. http://dx.doi.org/10.1002/(SICI)1098-2736(199903)36:3<269::AID-TEA3>3.0.CO;2-T

Anamuah-Mensah, J. (1998). Native science beliefs among Ghanaian students. Internal Journal of Science Education, 20(1), 115-124. http://dx.doi.org/10.1080/0950069980200108

Atwater, M. M. (1994). Research on Cultural Diversity in Science Classroom. In Dorothy L. G., Handbook on Research on Science Teaching and Learning. Macmillan, New York.

Cobern, W. W. (1993). Contextual constructivism: The Impact of Culture on the Learning and Teaching of Science. In K. G Tobin (Ed.), The practice of constructivism in science Education (pp. 51-69). Hillsdale, NJ Lawrence Erlbaum Associates, Inc.

Cobern, W. W. (1996). Constructivism and Non-Western Science Education Research. International Journal of Science Education, 4(3), 287-302.

Driver, R. (1989). Changing Conceptions. In Adey, P et al (Eds.), Adolescent Development and School Science, 79- 99. London, The Falmer Press.

Driver, R., \& Bell, B. (1986). Students' thinking and the learning of science: a constructivist view. School Science Review, 67(2), 443-456.

Good, L. T., \& Brophy, J. (1995). Contemporary Educational Psychology (5th ed.). New York, Longman Publishers.

Gray, B. (1998). Towards accessible science for pupils in rural areas: Issues of curriculum, teaching, and in -service support for teachers. In Ogunniyi M. B. (Ed.), Promoting Public Understanding of Science in Southern Africa. SSME, University of Western Cape.

Kraft, C. H. (1998). Culture, Worldview and Contextualization. Retrieved January 29, 2013, from http://www.mysite.verizon.net

Lewis, E. L., \& Linn, M. C. (2003). Heat Energy and Temperature Concepts of Adolescents, Adults and Experts: Implications for Curriculum Improvements. Journal of Research in Science Teaching, 40, Supplement, 5155-5175.

Moddock, M. N. (1981). Science education: An anthropological viewpoint. Studies in Science Education, 8, 1-26. http://dx.doi.org/10.1080/03057268108559884

Morris, R. W. (1983). Science and Technology Education and National Development. Paris: McGlashan Press.

Odhiambo, T. R. (1972). Understanding of Science, The Impact of the African View of the Nature of Science. In Gilbert, P. G., \& Lovegrove, M. N. (Eds.), Science Education. London. Heinemann Educational Books Ltd.

Ogunniyi, M. B. (1980). Traditional African Culture and Western Science. In Eke, \& Ashivaja, A. (Eds.), Nigeria Since Independence volume on Culture. Heinemann Educational Books Ltd.

Ogunniyi, M. B. (1984). Are the gods dead? Testing for relative influence of supernatural forces among Yoruba youths. Working paper No. 2 submitted to the International Development Research Council (IDRC), Ottawa, Canada.

Ogunniyi, M. B. (1985). Problems of Science Education Relative to the Nature of Scientific Concepts and Generalizations in Developing Countries. In Ukoh, F. M. A. (Ed.), What is Science? Problems of Teaching Science and Research in Nigerian Universities. Nigeria: Heinemann Education Books Ltd.

Ogunniyi, M. B. (1988). Adapting Western Science to Traditional African Culture. International Journal of Science Education, 10(1), 1-9. http://dx.doi.org/10.1080/0950069880100101

Okere, M. I. O., \& Keraro, F. N. (2002). Cultural Influences on Childhood Science Education. The Kenyan Experience. Egerton Journal, Humanities, Social Sciences and Education Series, 4, 141-153.

Pauka, S., Treagust, D. F., \& Waldrip, B. (2005). Village Elders' and Secondary School Students' Explanations of Natural Phenomena in Papua New Guinea. International Journal of Science and Mathematics Education (IJSME), 3(2), 213-238. http://dx.doi.org/10.1007/s10763-004-6529-2

Piaget, J. (1964). Development and Learning. Journal of Research in Science Teaching, 2, 176-186. http://dx.doi.org/10.1002/tea.3660020306 
Shumba, O. (1995). Science Teachers' Assessment of the Interaction of Indigenous African Culture with Science Education in Zimbabwe. Zimbabwe Journal of Educational Research, 7(3), 258-299.

UNESCO. (1999). Declaration on science and the Use of Scientific Knowledge. Text adopted by the World Conference on Science. Retrieved May 10, 2007, from http://www.unesco.org/science/wcs/declaration-e.htm

Van Eijck, M., \& Roth W. M. (2007). Improving Science Education for Sustainable Development. Retrieved February 5, 2012, from http://ww.plosbiology.org

Wikipedia. (2007). Culture. Retrieved May 10, 2007, from http://www.en.wikipedia.org./wiki/culture 